\title{
Reação motivacional docente do Curso de Graduação em Ciências Contábeis sob a perspectiva da Teoria Atribucional
}

\section{Alini da Silva, Caroline Sulzbach Pletsch, Vania Tanira Biavatti}

\author{
Universidade Regional de Blumenau \\ Universidade Regional de Blumenau \\ Universidade Regional de Blumenau \\ Programa de Pós Graduação em Ciências Contábeis
}

Poucos estudos preocupam-se com a investigação das causas da motivação docente. Os professores devem ser considerados como seres humanos, atores sociais com problemas e perspectivas, que lutam para atingir seus objetivos e ter uma carreira plena. São motivados por causas, como outro profissional, e entendendo-se estas causas pode-se trabalhar para a melhora do trabalho docente e o processo eficaz do ensino e aprendizagem. Desta forma, o objetivo do presente estudo foi analisar a reação motivacional de docentes do curso de Ciências Contábeis sob a perspectiva da Teoria Atribucional. A metodologia utilizada foi descritiva, levantamento de dados e quantitativa. Aplicou-se questionário aos docentes do curso de graduação em Ciências Contábeis de três instituiçóes do Estado de Santa Catarina. A análise dos dados foi realizada por meio da Técnica de Escalonamento Multidimensional com a utilização do software SPSS ${ }^{\bullet}$. Os resultados apontaram como motivos dos docentes do curso de graduação em Ciências Contábeis em exercer a profissão: o amor pela carreira; ensino e pesquisa; relacionamento interpessoal; plano de carreira; satisfaçáo pessoal e profissional; atividade junto a uma universidade; financeiro; aprendizado e conhecimento; vocaçáo e status profissional. O relacionamento dos docentes com os alunos e seus colegas de trabalho, o esforço e sorte foram às principais causas evidenciadas sobre a motivação destes profissionais.

Palavras-chave: Motivação docente, teoria da atribuição, causas e efeitos.

\section{Motivation of Professors in the Undergraduate Course of Accounting. Perspective of the Attribution Theory}

Few studies research about the causes of teacher motivation. Teachers should be considered as human beings and social actors, with problems and perspectives, people who struggle to achieve their goals and have a full career. They are motivated like any other professional, and by understanding these causes we can work on improving teaching and the effective process of teaching and learning. Thus, the aim of this study is to analyze the motivation of Accounting teachers from the perspective of attribution theory. The methodology used was descriptive and quantitative data collection approach. A survey was conducted among Accounting professors from three institutions in the State of Santa Catarina. Data analysis was performed using multidimensional scaling with SPSS software. Results pointed out the motives Accounting professors have to exercise their profession: love for the career; teaching and research; interpersonal relationships; career path; personal and professional satisfaction; working for a university; financial; learning and knowledge; 
vocational and professional status. The relationship between professor, students and their co-workers, effort and luck were the main causes of the motivation among these professionals.

Keywords: teacher's motivation, attribution theory, causes and effects.

\section{Motivación de los profesores de la carrera de Contabilidad en virtud de la teoría de la atribución}

Pocos estudios se preocupan por investigar qué motiva a los docentes. Los maestros deben ser considerados como seres humanos, actores sociales con problemas y perspectivas, personas que luchan por alcanzar sus metas y tener una carrera plena. Ellos están motivados por distintas causas, como cualquier otro profesional, y al comprender estas causas se puede trabajar para mejorar el trabajo de docencia y el proceso efectivo de enseñanza y aprendizaje. Por lo tanto, el objetivo de este estudio fue analizar la motivación de los docentes de la carrera de Contabilidad desde la perspectiva de la teoría de la atribución. La metodología utilizada fue descriptiva y cuantitativa. Se hizo un cuestionario dirigido a profesores que enseñan la carrera de Contabilidad en tres instituciones del Estado de Santa Catarina. Se analizaron los datos utilizando la técnica de escalamiento multidimensional y el software SPSS. Los resultados señalaron los motivos por los que los profesores de Contabilidad ejercen la profesión: amor por la carrera; enseñanza e investigación; relaciones interpersonal; línea de carrera; satisfacción personal y profesional; trabajo para una universidad; financiera; el aprendizaje y el conocimiento; vocación y status profesional. La relación entre profesores, alumnos y sus compañeros de trabajo, esfuerzo y suerte fueron las principales causas de motivación en estos profesionales.

Palabras clave: la motivación del profesor, la teoría de la atribución, causas y efectos.

\section{Introdução}

A motivação de docentes ao longo dos anos tem sido alvo de muitas discussóes, porém ainda não se chegou a uma conclusão se esta determina a forma de agir destes profissionais na execução de suas atividades de forma expressiva e eficaz (Vaz, 2010). Para Telfer e Swan (1986) a motivaçáo do professor em realizar com satisfação seu trabalho emerge da própria natureza de sua atividade. Locke (1984) por sua vez, contribui dizendo que a satisfação no trabalho é uma resposta emocional por parte do indivíduo às atividades que exerce.

Moreira (2011) acredita que os professores são como os demais profissionais, motivados por incentivos, sucessos, realizaçóes e satisfação. Teorias motivacionais como a da abordagem da expectação de Vroon, a da realização de Atkinson, da aprendizagem social de Rotter, e da atribuiçâo de Heider, preocupam-se em analisar a motivação humana, as quais podem verificar os aspectos motivadores de docentes.

A Teoria da Atribuição consiste em atribuir causas para explicar determinado acontecimento e que estas são atribuídas pelo próprio indivíduo. As causas atribuídas podem ser tanto internas, como externas, controláveis ou incontroláveis, instáveis ou estáveis. Causas internas são provenientes do próprio indivíduo, como habilidade e esforço; causas externas decorrem da atribuição de fatores externos, como sorte. A causa pode ser controlável ou incontrolável, no aspecto de influenciar ou não no seu controle. Ainda, as causas atribuídas por indivíduos podem ser estáveis ou instáveis, o que corresponde ao fato de permanência no tempo (Weiner, 1992 apud Sales, 2010; Ferreira et al., 2002). 
Essas dimensóes causais trazem como consequência ao indivíduo expectativa de sucesso ou fracasso e emoções tais como motivação ou frustração.

De acordo com Sales (2010) a Teoria da Atribuição encontra-se presente em estudos sobre motivação em Psicologia Social e Educacional, há quase quatro décadas. Neste contexto, a fim de entender as reaçóes motivacionais de docentes, a partir da concepção de Weiner, verifica-se a seguinte questão problema: Qual a reação motivacional de docentes do curso de Ciências Contábeis sob a perspectiva da Teoria Atribucional? Com o intuito de responder esta questáo o estudo tem por objetivo analisar a reação motivacional de docentes do curso de Ciências Contábeis sob a perspectiva da Teoria Atribucional.

De acordo com Moreira (2011) não se pode sugerir que o desempenho do professor está apenas e táo somente ligado à motivação, nem que quanto maior for à satisfação do professor, maior será o seu desempenho no trabalho, mas é importante a realização de pesquisas a fim de investigar o que realmente motiva os professores, com especial atenção à natureza da interação entre o desenvolvimento do indivíduo e da organização.

Sales (2010), Ganda e Boruchovitch (2011) utilizaram a Teoria Atribucional em meio acadêmico. Entretanto, constataram pouca ou nenhuma utilização desta teoria em análise, na motivação docente. Justifica-se então este trabalho, pela utilização da Teoria Atribucional para verificar o nível de motivação de docentes específicos do Curso Superior de Ciências Contábeis, e quais as causas atribuídas por eles que influenciam nesta motivação, a fim de auxiliar na resoluçáo de problemas relacionados ao processo de ensino e aprendizagem.

De acordo com Viana (2008) há ausência de estudos específicos referentes ao tema e, as contribuiçóes que pode trazer à sociedade, através da otimização dos sistemas educacionais, obtendo uma visão mais aprofundada sobre o comportamento dos docentes no tocante à motivação para o trabalho.

Santos (2001) traz menção de que o bom ensino é realizado a partir do entusiasmo do docente. $\mathrm{O}$ docente por ser a peça principal no processo de ensino e aprendizagem dos alunos, necessita estar motivado, pois quanto mais motivado estiver, melhor será seu empenho para o aprendizado dos alunos. O salário, reconhecimento profissional e realização pessoal, como fatores extrínsecos e intrínsecos, respectivamente, podem ser considerados fatores da motivação docente (Oliveira, Donato, Dos Santos \& Dantas, 2009).

Desta forma, este estudo organiza-se da seguinte forma: a introdução que se apresenta nesta seção, com o objetivo, problema e justificativa do estudo, a seção 2- Motivação Docente traz as principais referenciais acerca da motivação docente a partir da Teoria Atribucional e alguns estudos relacionados. Na seção 3- Procedimentos Metodológicos, descreve-se a metodologia utilizada neste trabalho e na seção 4- Descrição e Análise dos Dados, ponderações a respeito dos dados obtidos. E, ao final as consideraçóes desta pesquisa, seguidas das referências bibliográficas.

\section{Motivaçáo docente}

A motivação humana é verificada em indivíduos ativos e energizados, com prazer em realizar suas atividades profissionais ou pessoais. Quando há falta de impulso ou inspiração do indivíduo em agir para a consecução de suas atividades rotineiras, o mesmo pode apresentar-se desmotivado (Ryan \& Deci, 2000).

No contexto da motivação docente é importante que os professores sejam considerados como seres 
humanos, atores sociais com problemas e perspectivas, que lutam para atingir seus objetivos e ter uma carreira plena, ou ainda, lutam para sobreviver em seu trabalho. Portanto, torna-se necessário a realização de pesquisas interpretativas a fim de identificar o que o profissional docente realmente sente, pensa e como age em salas de aula e no contexto do ensino com suas causas e efeitos. A satisfação de profissionais no trabalho pode afetar a produtividade do trabalhador, o absenteísmo e a rotatividade, colaborando ou não com a eficiência organizacional, além do bem estar físico e mental que gera ao indivíduo (Moreira, 2011).

Segundo Locke (1984) a satisfação no trabalho antes de tudo, é uma resposta emocional por parte do indivíduo às atividades que exerce em determinada organização. Por sua vez, Jesus e Santos (2004) acreditam que a carreira docente possui diferentes níveis de motivaçáo.

De acordo com Antunes (2012), a motivação é um processo que está ligado ao crescimento do ser humano em cada etapa de sua vida e desenvolvimento, revelada em desejos, intencionalidades e aspirações, que se dá, a partir de referências familiares, escolares e sociais. A motivação correspondente ao esforço e à tenacidade exercidos por indivíduo para fazer algo ou alcançar algo, é parte integrante do comportamento humano (Viana, 2008).

De acordo com Weiner (1992) como os seres humanos são capazes de planejar suas ações, estes são informados a respeito de possíveis opçóes comportamentais. Moreira (2011) argumenta que as instituiçóes de ensino acreditam que os professores, dispondo de todo o suporte necessário para ministrar suas aulas, são naturalmente motivados, os quais devem manter a dedicação e o cumprimento de suas obrigaçóes eficazmente e que a maior fonte de satisfaçáo do professor, tradicionalmente, é o ato de ensinar.
Os motivos de um profissional exercer a docência ou permanecer como professor são de difícil identificação, devido aos baixos salários, condiçóes precárias de trabalho, atos de violências contra esses profissionais, doenças decorrentes da profissão, desvalorização da profissáo e esquecimento do governo quanto a melhora da educaçáo (Oliveira et al., 2009).

Devido ao desgaste de docentes por motivos anteriormente abordados e pela importância que possuem para o ensino ser de qualidade em instituiçôes, é necessário a compreensão dos motivos que fazem com que os docentes abandonam a profissão, bem como os motivos que os levaram a exercer a docência, suas crenças e motivaçôes. A atual literatura não deixa claro o motivo de indivíduos escolherem como profissão a docência, enquanto muitos abandonam a carreira (Thomson, Turner \& Nietfeld, 2012).

O comportamento do profissional docente é influenciado por suas convicçôes, nível de esforço, persistência, interesse em ensinar, enfrentamento de obstáculos, capacidades e habilidades, que por sua vez promove a aprendizagem significativa dos alunos, desde que o docente gerencia estes fatores mediadores (Iaochite, Azzi, Polydoro \& Winterstein, 2011).

O ensino promove a ampliação do capital intelectual e cultural de estudantes pela transmissão de conhecimento construído, vivências e experiências profissionais passadas, a fim de gerar a capacidade de pensamento, reflexão, análise e síntese dos estudantes. O professor deve lidar com a sua própria motivaçáo e a de seus alunos com a finalidade de desenvolver uma sociedade mais justa e igualitária por meio da educaçáo (Cavalcante, Bissoli, Almeida \& Pimenta, 2011).

Quatro elementos são essenciais para o processo de ensino: o aluno, a escola, o conteúdo e o professor. As dimensóes que o professor deve deter para o processo

Contabilidad y Negocios (10) 20, 2015 / ISSN 1992-1896 
eficaz de ensino estão relacionados com o bom relacionamento com seus alunos, a dimensão cognitiva com aspectos intelectuais e técnicos didáticos, a atitude de como educar, sua inovaçáo, e comprometimento (Santos, 2001).

Neste sentido, Skaalvik e Skaalvik (2011) trazem que as emoçôes positivas dos professores estão interligadas com as relaçóes com seus colegas de trabalho e familiares. As emoçóes negativas dos docentes referem-se à pressão do tempo e sua disciplina. Por sua vez, estas emoçóes influenciam a satisfação do profissional em seu trabalho, que são preditivas para a motivação do docente em exercer a carreira ou abandoná-la. Administradores de instituiçóes de ensino devem perceber estas influências nas emoçóes de docentes e satisfação a fim de tomar medidas para auxiliá-los.

\section{Teoria da Atribuiçáo}

A Teoria da Atribuição é uma das teorias sobre cognição social, em que o pioneiro nos estudos neste campo foi Fritz Heider em 1944 com o trabalho intitulado: «Social perception and phenomenal causality». $\mathrm{O}$ autor faz menção de que os indivíduos tem a necessidade de atribuir causas para explicar determinado acontecimento, bem como seus efeitos. Pelo estabelecimento de elos entre as causas e efeitos, os indivíduos conseguem prever ainda os seus comportamentos futuros (Dela Coleta \& Godoy, 1986).

Bernard Weiner foi o criador da Teoria da Atribuição Causal, em que sistematizou causas para explicar os resultados obtidos, como sucesso ou fracasso (Antunes, 2012). De acordo com Dela Coleta e Godoy (1986) pesquisas em psicologia social trazem como resultado de que o ser humano náo se preocupa com os fatos que ocorrem ao seu redor e que ainda, explicam estes por meio da determinação de possíveis causas.
Ganda e Boruchovitch (2011) contribuem, dizendo que a atribuição de causalidade procura atribuir causas a situações que acontecem com o próprio indivíduo e com as demais pessoas. As pesquisas contemporâneas em motivação, não mais se baseiam em teorias do impulso ou dos instintos, mas em percepção social e cognitivas. Os seres humanos são essencialmente motivados por incentivos, sucessos, realizaçóes e satisfação (Moreira, 2011).

Segundo Cornachione Junior, Cunha, Luca e Ott (2010) a Teoria da Atribuição é considerada importante na transformação do desempenho de indivíduos, pela identificação de causas como a educação e experiências profissionais. Existe uma forte tendência dos indivíduos associar o sucesso em seu desempenho a fatores internos e o fracasso a fatores externos.

A Teoria da Atribuição proposta por Weiner (1979, 1984, 2000, 2004) apud Sales (2010) tem como objetivo compreender porque um evento ocorreu, quando se obteve um resultado inesperado. Os indivíduos buscam entender as causas dos acontecimentos. Quando obtêm resultado negativo de determinada atividade, atribuem causas ao seu fracasso, diminuindo a surpresa gerada pelo ocorrido, e aumentando as chances de sucesso no futuro, por conhecer o motivo do fracasso. No contexto da aprendizagem, o sucesso e o fracasso são atribuídos à capacidade, inteligência, aspectos motivacionais, pessoas de seu convívio, fatores fisiológicos como saúde e maturidade, dificuldade ou facilidade da tarefa e sorte.

Weiner (1984) apud Sales (2010) considera ainda que as atribuições causais conduzem consequências motivacionais, como expectativas de sucesso ou fracasso futuro. Após o sucesso, quando as causas atribuídas são internas, estáveis e controláveis (esforço) ou mesmo não controláveis (capacidade) há expectativas 
aumentadas. Porém, após situação de fracasso, com causas atribuídas internas, estáveis e não controláveis (capacidade), as expectativas sofrem decréscimo. Ainda, se atribuir o insucesso à falta de esforço (causa interna, instável e controlável), as chances de ser bem sucedido no futuro podem ser aumentadas, empenhando-se mais na próxima oportunidade.

\section{Estudos relacionados}

Apresentam-se nesta seção estudos relacionados com a motivação docente do curso de Ciências Contábeis sob a perspectiva da Teoria Atribucional. Entretanto, localiza-se nas pesquisas o tema motivação docente pela perspectiva de outras teorias motivacionais, não sendo a da atribuição, ou ainda, a utilização da Teoria Atribucional em estudos sobre alunos.

Viana (2008) objetivou conhecer os fatores motivacionais presentes no comportamento de docentes da rede de ensino fundamental pública do Estado da Paraíba. Este estudo abrangeu uma população composta por 874 profissionais. As teorias de base que deram sustentação a análise proposta foram extraídas dos trabalhos de Herzberg (1972), Maslow (1971), McClelland (1971), McGregor (1973), Vroom (1964), as quais defendem que o trabalho por si só já é motivador ao ser humano. Como resultados, verificou-se que a necessidade de auto-realização, da possibilidade de mostrar competência, de contribuir para formar pessoas capazes de realizar-se como ser humano e como cidadãos foram às atitudes motivacionais dos docentes analisados.

Vaz (2010) averiguou os fatores que determinam a motivação de professores do ensino médio e o papel exercido pelos gestores com o mesmo propósito. A amostra foi composta por 68 professores e 7 gestores de duas instituiçóes educacionais públicas de nível médio, situadas no Distrito Federal. Por meio da aplicação de questionário, verificou-se que os professores esperam atitudes dos gestores no sentido de motivá-los, e os gestores não associam a motivação dos professores à gestão.

Sales (2010) investigou as causas que os professores de matemática atribuem ao fracasso de seus alunos, comparando-as com as percepçóes destes. Por meio da Teoria Atribucional, foram abordados cinco professores de matemática e 407 estudantes, de uma Escola Estadual do norte do Paraná, por meio de dois questionários, um para os alunos e outro para os professores. Constataram que os alunos que já reprovaram em matemática ou tiveram fracasso possuem auto percepçáo negativa da sua capacidade e do professor; tanto meninas, como meninos não repetentes perceberam mais positivamente seu professor de matemática do que os alunos que já reprovaram; os que nunca enfrentaram reprovação também se apresentaram mais motivados em relação à disciplina. Meninos e meninas repetentes acreditam que seu professor possui expectativa negativa em relação a eles, e os meninos que já reprovaram atribuíram seu fracasso à falta de capacidade. Os docentes demonstraram expectativas negativas mais altas que seus estudantes e atribuíram o fracasso de seus alunos principalmente à falta de motivação, falta de base anterior, falta de apoio familiar e falta de estratégias.

Mozini (2010) estudou os fatores de motivação e satisfação no trabalho docente em uma instituição de ensino superior particular. A amostra foi composta por 15 professores dos cursos de graduação em Pedagogia e Psicologia, na faixa etária de 26 a 55 anos, aproximadamente. A fundamentação teórica foi norteada nas teorias de Maslow, McGregor e Herzberg sobre motivaçáo. Os resultados apresentaram que o trabalho docente é motivador quando os papéis a 
serem desempenhados são claros, as tarefas são desafiadoras e quando há supervisores que apresentam um estilo apoiador de liderança. As atividades burocráticas, o relacionamento entre colegas, o desempenho docente e a identificação profissional são fatores que não causam desmotivação, pois estas condições são básicas para a promoção do bem-estar do funcionário.

Ganda e Boruchovitch (2011) apresentaram uma análise da produção científica acerca das atribuições de causalidade de estudantes de ensino superior, com destaque nos cursos de formação de professores. A análise compreendeu o período entre 1998 e 2011, com revisão de publicaçóes de alunos universitários, inseridos em cursos de formação de professores e áreas afins, e de professores em exercício, tanto nacional, como internacional. Os resultados mostraram que há um maior número de trabalhos realizados internacionalmente. Constatou-se também que há poucos estudos relacionados às atribuiçóes causais de alunos no curso de formação de professores e de docentes na ativa, tanto em nível nacional como internacional.

Moreira (2011) investigou a motivação do professor como uma dimensão esquecida em pesquisas. Por meio de pesquisa bibliográfica, este acredita que teorias de psicologia social, tais como: da expectação (Vroom), a teoria da motivação para a realização (Atkinson), a teoria da aprendizagem social (Rotter) e a teoria da atribuição (Heider) podem ser utilizadas para a realização de novos estudos, a fim de identificar a real motivação docente. Como estudos futuros, incentivou a investigação de experiência individual de docentes dentro de instituiçóes, as emoçóes destes, como percebem seus colegas, o mundo do trabalho docente, e o meio social, para verificar como influenciam na qualidade do ensino e as relaçóes interpessoais que caracterizam a atividade do profissional da educação.

\section{Procedimentos Metodológicos}

O presente estudo tem por objetivo analisar a reação motivacional de docentes do curso de Ciências Contábeis sob a perspectiva da Teoria Atribucional, caracterizando-se como descritivo. Segundo Raupp e Beuren (2004) a pesquisa descritiva consiste em observar os fatos, classificando e interpretando-os, sem que o pesquisador interfira neles e por meio de técnicas precisas, métodos, modelos e teorias que conferem validade científica à pesquisa.

No que se refere aos procedimentos, a pesquisa classifica-se como levantamento de dados, pela coleta de informaçóes de uma amostra definida, para conhecer o comportamento destes (Silva, 2003). Quanto à abordagem do problema, a pesquisa se enquadra como quantitativa, pelo tratamento dos dados por meio de métodos e técnicas estatísticas (Richardson, 1989).

\section{População e amostra}

A população do presente estudo compreende docentes do curso de graduação em Ciências Contábeis de instituiçóes do ensino superior do estado de Santa Catarina. A amostra foi composta por 43 docentes do curso de Ciências Contábeis de 3 instituiçôes de ensino superior do estado de Santa Catarina, em decorrência do fácil acesso a estas instituiçóes. Esta amostra fez-se necessária para a aplicação de método estatístico e a consecução do objetivo proposto.

\section{Coleta e análise dos dados}

A coleta dos dados se deu por meio de questionário com perguntas sobre o perfil dos respondentes, bem como fatores relacionados à motivação docente sob a perspectiva da Teoria Atribucional. Com o objetivo de garantir a confiabilidade do instrumento de levantamento de dados, o questionário elaborado foi 
submetido à 5 mestrandos de um Curso de Pós Graduação Strictu Senso em Ciências Contábeis que já atuam na docência. Para este fim, foi entregue o questionário juntamente com formulário de validação, para que verificassem se as questóes estavam atendendo ao objetivo proposto. Todas as contribuiçóes foram acatadas e utilizadas para a melhoria do questionário.

As perguntas relacionadas ao perfil dos respondentes foram fechadas, as relacionadas com as causas da motivação docente foram de forma likert pontuadas de 1 a 5, e a última questáo apresentou-se de forma aberta, a fim de relacionar os principais motivos dos docentes em exercer a carreira. Para a análise dos dados foi utilizado a Técnica Escalonamento Multidimensional, por meio do software SPSS ${ }^{\ominus}$ O Escalonamento Multidimensional "[...] é uma técnica exploratória multivariada que permite representar de forma parcimoniosa, num sistema dimensional reduzido, as proximidades (semelhanças/dissemelhanças) entre sujeitos ou objetos [...]" (Marôco, 2011 p. 567).

\section{Descriçáo e análise dos dados}

Nesta seção apresenta-se o perfil dos docentes, a análise das causas atribuídas à motivação docente por meio da Técnica Escalonamento Multidimensional, bem como os principais motivos que os docentes atribuíram ao exercício da profissão. A seguir na tabela 1 demonstrase o perfil dos docentes da amostra em estudo.

Visualiza-se nesta tabela que a maioria dos docentes possuem idade entre 41 a 50 anos, perfazendo um total de dezoito docentes. Onze respondentes tem idade entre 31 a 40 anos, dez docentes possuem mais de 51 anos e quatro entre 20 e 30 anos. Quanto ao gênero, vinte e seis docentes são do gênero masculino, onze do feminino e seis não especificaram.

Tabela 1. Perfil dos docentes

\begin{tabular}{lclc} 
Idade & Quantidade & Formaçáo & Quantidade \\
20 a 30 & 4 & Administração & 5 \\
31 a 40 & 11 & Ciências Contábeis & 24 \\
41 a 50 & 18 & Ciências Contábeis e Administração & 2 \\
Mais de 51 & 10 & Ciências Contábeis e Direito & 1 \\
Gênero & Quantidade & Ciências Contábeis, Administração e Direito & 1 \\
Feminino & 11 & Ciências Sociais & 1 \\
Masculino & 26 & Direito & 2 \\
Náo especificado & 6 & Economia & 1 \\
Instituiçáo & Quantidade & Engenharia civil & 1 \\
Comunitária & 27 & Letras & 1 \\
Náo especificado & 2 & Matemática & 1 \\
Privada & 10 & Psicologia & 1 \\
Pública & 4 & Sistemas de Informação & 1 \\
- & - & TPT - Eletromóveis & 1 \\
\hline
\end{tabular}

Fonte: Dados da pesquisa. 
Em relação à instituição de ensino superior na qual exercem atividade atualmente, vinte e sete docentes atuam em entidade comunitária, dez em privada, quatro em pública e dois não especificaram. A formação acadêmica dos docentes em análise correspondeu principalmente ao curso de ciências contábeis, com vinte e quatro formações nesta área. Cinco docentes são da área de administração, dois possuem formação em direito, dois em ciências contábeis e administração. Os demais, um em ciências sociais, economia, engenharia civil, letras, matemática, psicologia, sistemas de informação e TPT Eletromóveis. Ainda, um destes possui graduação em ciências contábeis, administração e direito e outro em ciências contábeis e direito.

Depois de realizado o teste de confiabilidade, aplicouse o questionário à amostra e sobre os dados levantados realizou-se a Técnica Escalonamento Multidimensional. Na tabela 2 apresentam-se as medidas de stress e ajuste dos dados.

Tabela 2. Medidas de stress e ajuste

\begin{tabular}{ll} 
Stress bruto normalizado & 0,00317 \\
Stress-I & $0,05626^{\mathrm{a}}$ \\
Stress-II & $0,07175^{\mathrm{a}}$ \\
Stress S & $0,00328^{\mathrm{b}}$ \\
Dispersão contabilizada para (D.A.F.) & 0,99683 \\
Coeficiente de congruência de Tucker & 0,99842 \\
\hline
\end{tabular}

PROXSCAL minimiza o stress bruto normalizado.

a. Fator de escala ideal $=1,003$.

b. Fator de escala ideal $=0,998$.

Fonte: Dados da pesquisa.

Referente à qualidade de ajuste do modelo descrito na tabela 2, de acordo com Corrar, Paulo e Dias Filho (2007), o indicador de Stress representado por 0,05 é considerado justo, ou seja, quanto menor o valor do indicador melhor é o ajuste, pois possui pequenos erros no modelo. Desta forma, o modelo do presente estudo é considerado justo e com pequenos erros. Quanto ao indicador de dispersão contabilizada para (D.A.F) de acordo com Marôco (2011) o valor de 0,9 representa o veredito muito bom ao modelo em estudo.

A seguir visualizam-se na tabela 3 as coordenadas finais do modelo que representa as causas atribucionais da motivação docente.

Tabela 3. Coordenadas finais do modelo

\begin{tabular}{lcc}
\cline { 2 - 3 } & \multicolumn{2}{c}{ Dimensão } \\
\hline Experiência em anos & 2,047 & 2 \\
Escolaridade & $-0,323$ & 0,023 \\
Sucesso & $-0,095$ & 0,360 \\
Renda & $-0,231$ & 0,020 \\
Gestão universidade & $-0,189$ & 0,150 \\
Sorte & $-0,439^{*}$ & $-0,130^{*}$ \\
Esforço & $-0,179^{*}$ & $-0,184^{*}$ \\
Relação alunos & $-0,102^{*}$ & $-0,037^{*}$ \\
Relação colegas & $-0,118^{*}$ & $-0,115^{*}$ \\
Cursos & $-0,304$ & 0,002 \\
Motivação & $-0,067^{*}$ & $-0,147^{*}$ \\
\hline
\end{tabular}

* pertencentes ao quadrante 00:00.

Fonte: Dados da pesquisa.

Com base na tabela 3 foram verificadas as coordenadas de cada causa possível da motivação docente. A partir da coordenada da motivação, que se encontra dentro do quadrante 00:00, pode-se verificar as causas que também se encontram nesta limitação. $\mathrm{Na}$ figura 1 é possível visualizar o gráfico destas coordenadas.

De acordo com a figura 1 as causas relacionadas à motivaçáo docente que se encontram no mesmo quadrante da motivação de 00:00, são: relação com os colegas de trabalho, relação com os alunos, o esforço pessoal e a sorte. Desta forma, considera-se que as relaçóes com colegas e alunos, o esforço e a sorte são as causas mais próximas relacionadas com a motivação docente. 
Figura 1. Gráfico das distâncias

Pontos de objeto

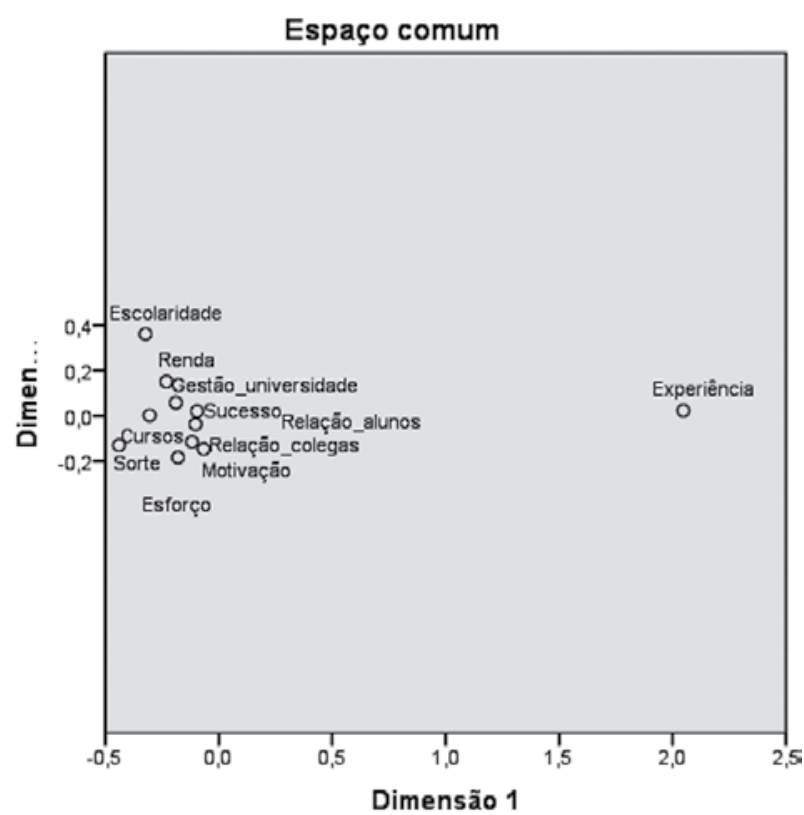

Fonte: Dados da pesquisa.

Por sua vez, os anos com experiência docente, a escolaridade, o sucesso, a renda, a gestão da universidade e os cursos realizados por tais profissionais são causas relacionadas com a motivação docente, porém por não constarem no quadrante de 00:00, são causas mais afastadas da motivação docente. Pode-se perceber que os anos com experiência docente foi a causa mais afastada da motivação.

Quanto às respostas dos docentes sobre os principais motivos para exercerem a docência, foi possível separar as respostas em dez categorias, conforme explicita o quadro 1.

Neste contexto pode-se perceber que os principais motivos dos docentes do curso de graduação em Ciências Contábeis em exercer a profissão, são: o amor pela carreira; ensino e pesquisa; relacionamento interpessoal; plano de carreira; satisfação pessoal e profissional; atividade junto a uma universidade; financeiro; aprendizado e conhecimento; vocação e status profissional. $\mathrm{E}$ as principais causas da sua motivação em realizar tal atividade são pertinentes ao relacionamento com colegas de trabalho e alunos, esforço pessoal e sorte.

Esses achados de pesquisa vão ao encontro dos resultados encontrados por Santos (2001), Viana (2008), Mozini (2010), Skaalvik e Skaalvik (2011), e Iaochite et al. (2011), os quais destacam fatores tais como: esforço, interesse em ensinar, capacidades e habilidades, relacionamento com alunos e colegas de trabalho, auto realização e a formação de acadêmicos, que também foram identificados no presente estudo, como motivadores dos profissionais docentes.

Dado o exposto, a causa mais evidenciada como fator de motivação de profissionais docentes tanto do curso de graduação em Ciências Contábeis como em demais cursos verificados com base na pesquisa bibliográfica, foi o bom relacionamento com os alunos e seus colegas de trabalho. De acordo com Santos (2001) e Skaalvik e Skaalvik (2011) o bom relacionamento com alunos e colegas de trabalho contribui no processo de ensino eficaz e traz emoçôes agradáveis aos professores, que por sua vez, motivam-se a continuarem na profissão.

\section{Consideraçóes finais}

O objetivo proposto no presente estudo foi de analisar a reação motivacional de docentes do curso de graduação em Ciências Contábeis sob a perspectiva da Teoria Atribucional. A metodologia utilizada para a consecução deste escopo foi descritiva, de levantamento de dados e quantitativa. Para o levantamento de dados foi utilizado questionário, aplicado a docentes do curso de graduação em Ciências Contábeis de 3 instituiçôes de ensino superior do estado de Santa Catarina. A análise dos dados foi auxiliada pela Técnica de Escalonamento Multidimensional no software SPSS. 


\section{Quadro 1. Motivos do exercício da docência}

\begin{tabular}{|c|c|}
\hline Motivos & Trechos das respostas \\
\hline Amor & $\begin{array}{l}\text { "Amo o que faço, gosto de estudar e estar envolvida com aprendizagem, valorizar a educação, } \\
\text { sentir-me realizada em ensinar" (Docente no 26). }\end{array}$ \\
\hline Ensino e Pesquisa & $\begin{array}{l}\text { "Despertar a compreensão dos acadêmicos, promover o exercício da razão, ensinar a pensar certo, } \\
\text { transformar os acadêmicos, estar envolvido na educação" (Docente no } 24 \text { ). } \\
\text { "Realizaçáo profissional, instiga a busca constante pela pesquisa e aprendizado" (Docente no 43). }\end{array}$ \\
\hline $\begin{array}{l}\text { Relacionamento } \\
\text { interpessoal }\end{array}$ & "Porque gosto de me relacionar com pessoas e gosto de ensinar" (Docente no 2). \\
\hline Carreira docente & $\begin{array}{l}\text { "Gostar de trabalhar com o ensino, possibilidade de atualização profissional, perspectiva de car- } \\
\text { reira" (Docente no } 29 \text { ). }\end{array}$ \\
\hline $\begin{array}{l}\text { Satisfação pessoal e } \\
\text { profissional }\end{array}$ & $\begin{array}{l}\text { "Necessidade e satisfaçáo pessoal e profissional. Adoro a docência e estar no âmbito acadêmico. O } \\
\text { profissional se atualiza obrigatoriamente e se torna prazeroso o dia a dia" (Docente no 12). }\end{array}$ \\
\hline $\begin{array}{l}\text { Atividade junto a } \\
\text { uma universidade }\end{array}$ & $\begin{array}{l}\text { "Ficar em atividade junto a uma universidade, satisfaçáo pessoal, plano de carreira, caso modifi- } \\
\text { que o sistema de aposentadoria" (Docente no } 4 \text { ). }\end{array}$ \\
\hline Financeiro & "Complementação da renda" (Docente no 7). \\
\hline $\begin{array}{l}\text { Aprendizado e } \\
\text { conhecimento }\end{array}$ & $\begin{array}{l}\text { "Aprender mais, busca de novos conhecimentos, contato com pessoas para trocar ideias" (Docente } \\
\mathrm{n}^{\mathrm{o}} 15 \text { ). }\end{array}$ \\
\hline Vocação & "Vocaçāo" (Docente no 32). \\
\hline Status profissional & $\begin{array}{l}\text { "Satisfação profissional, retribuição, constante aprendizado, oferece um meio de destaque perante } \\
\text { os profissionais da área" (Docente no } 40 \text { ). }\end{array}$ \\
\hline
\end{tabular}

Fonte: Dados da pesquisa.

Os resultados apontaram como principais motivos dos docentes do curso de graduação em Ciências Contábeis em exercer a profissão: o amor pela carreira; ensino e pesquisa; relacionamento interpessoal; plano de carreira; satisfação pessoal e profissional; atividade junto a uma universidade; financeiro; aprendizado e conhecimento; vocação e status profissional.

Já as principais causas atribuídas pelos docentes em relação a sua motivaçáo estão associadas essencialmente ao relacionamento com seus colegas de trabalho e alunos, ao seu esforço pessoal e sorte. O que corrobora com os demais estudos, visto que apontam o relacionamento com os alunos e colegas de trabalho e o esforço como principais causas. Em relação à sorte identificada neste estudo, como causa de motivação docente, esta verifica-se de forma inédita, pois não foi constatada nos estudos relacionados.

A causa mais evidenciada como fator de motivação de profissionais docentes tanto na presente pesquisa como em demais estudos encontrados, foi o relacionamento que possuem com as partes relacionadas ao exercício da profissáo, tais como alunos e colegas de trabalho.

O bom ensino, segundo Santos (2011) é realizado a partir do entusiasmo docente, o qual é peça principal no processo de ensino e aprendizagem, necessitando estar motivado e empenhado na realização de suas atividades. 
Apresenta-se como contribuição da presente pesquisa, a identificação dos fatores motivadores de docentes do curso de ciências contábeis, visto que poucos estudos observaram esta temática. Constatou-se que os fatores motivadores dos docentes foram relacionamento com colegas e alunos, esforço pessoal e sorte. Desta forma, incentiva-se que gestores de recursos humanos de universidades realizem atividades entre docentes e alunos, a fim de gerar maior integração dentre estes, o que pode aumentar a motivação tanto dos professores, quanto dos alunos também, contribuindo consequentemente para o desempenho destes em sala de aula. Quanto ao fator motivador esforço pessoal do professor, como é uma característica intrínseca dos docentes, sugere-se que os mesmos busquem se aperfeiçoar com informaçóes sobre a área, o que pode auxiliar em suas aulas e consequentemente lhe gerar os sentimentos de valorização e motivação. Em relação à sorte dos professores, esta se torna subjetiva, visto que não depende do esforço do professor, universidade e alunos, entretanto, boas oportunidades aparecem para àqueles que se encontram preparados, sugerindo-se desta forma, a constante atualização do conhecimento.

Como limitação de estudo verificou-se a pouca quantidade de respondentes à pesquisa, apesar de tal limitaçáo náo ter comprometido os resultados do estudo. Sugere-se para pesquisas futuras, a utilização de outras teorias para detectar as causas relacionadas à motivação docente do curso de graduação em Ciências Contábeis, a fim de comparar os resultados com o presente estudo e a partir disto, aprofundar as reflexóes acerca dos resultados apresentados.

\section{Referências}

Antunes, D. D. (2012). Oficinas pedagógicas de trabalho cooperativo: uma proposta de motivação docente. Tese em Educação. Faculdade de Educação, Pontifícia Universidade Católica do Rio Grande do Sul, Porto Alegre.
Cavalcante, L. I. P., M. D. F. Bissoli, M. I. D. Almeida, S. G. A Pimenta (2011). Docência no ensino superior na área da saúde: formação continuada/desenvolvimento profissional em foco. Revista Eletrônica Pesquisa Educação, 3 (6), 162-182.

Cornachione Junior, E. B., J. V. A. Cunha, M. M. M. Luca \& E. Ott (2010). O bom é meu, o ruim é seu: perspectivas da teoria da atribuiçấo sobre o desempenho acadêmico de alunos da graduação em Ciências Contábeis. Revista Contabilidade \& Finanças - USP, 21 (53), 1-24. http://dx.doi.org/10.1590/s151970772010000200004

Corrar, L. J., E. Paulo \& J. M. Dias Filho (2007). Análise multivariada para os cursos de Administração, Ciências Contábeis e Economia. São Paulo: Atlas.

Dela Coleta, J. A. \& S. A. Godoy (1986). Atribuição de causalidade ao sucesso e fracasso e reaçóes emocionais: pesquisas brasileiras com os modelos de Bernard Weiner. Psicologia: Teoria e Pesquisa, 2, 145-156.

Ferreira, M. C., E. M. L. Assmar, A. G. Omar, H. U. Delgado, A. T. Gonzales, J. M. B. Silva, M. A. Souza \& M. C. F. Cisne (2002). Atribuição de causalidade ao sucesso e fracasso escolar: um estudo transcultural Brasil-Argentina-México. Psicologia: Reflexão e Crítica, 15 (3), 515-527. http://dx.doi.org/10.1590/s010279722002000300006

Ganda, D. R. \& E. Boruchovitch (2011). Atribuição de causalidade no ensino superior: análise da Produção científica. Estudos Interdisciplinares em Psicologia, 2 (1), 2-18. http://dx.doi.org/10.5433/2236-6407.2011v$2 \mathrm{n} 1 \mathrm{p} 2$

Iaochite, R. T., R. G. Azzi, S. A. J. Polydoro \& P. J. Winterstein (2011). Autoeficácia docente, satisfação e disposição para continuar na docência por professores de Educação Física. Revista Brasileira de Ciências do Esporte, 33(4).

Jesus, S. N. \& J. C. V. Santos (2004). Desenvolvimento Profissional e Motivação dos Professores. Revista Educação, 1 (52), 39-584.

Contabilidad y Negocios (10) 20, 2015 / ISSN 1992-1896 
Locke, E. (1984). Job satisfaction. In: Gruneberg M. \& T. Wall (Eds.), Social psychology and organizational behaviour (pp. 93-117). New York: John Wiley \& Sons.

Marôco, J. (2011). Análise Estatística com o SPSS Statistics. $5^{a}$ ed. Análise e Gestão de Informação Ltda.

Moreira, H. (2011). A investigação da motivação do professor: a dimensão esquecida. Revista Educação \& Tecnologia

Mozini, A. F. (2010). Motivação e satisfação no trabalho docente em uma instituição de ensino superior particular: estudo de caso. Dissertação em Educação. Universidade do Oeste Paulista - UNOESTE, Presidente Prudente São Paulo.

Oliveira, A. G. A., C. R. Donato, M. Dos Santos \& M. A. Dantas (2009). Principais fatores que motivam os professores de ensino de Ciências e/ou Biologia do município de Aracaju, Sergipe a lecionarem. Scientia Plena, 5(3).

Raupp, F. M. \& I. M. Beuren (2004). Caracterizaçáo da pesquisa em Contabilidade. In: Beuren, I. M. (Org.). Como elaborar trabalhos monográficos em contabilidade: teoria e prática. $2^{\mathrm{a}}$ ed. São Paulo: Atlas.

Richardson, R. J. (1989). Pesquisa social: métodos e técnicas. $2^{a}$ ed. São Paulo: Atlas.

Ryan, R. M. \& E. L. Deci (2000). Intrinsic and extrinsic motivations: Classic definitions and new directions. Contemporary educational psychology, 25 (1), 54-67. http://dx.doi.org/10.1006/ceps.1999.1020

Sales, K. F. S. (2010). As atribuiçōes causais de professores por fracasso escolar em matemática: comparação com percepçôes de seus alunos. Dissertação em Educação. Universidade Estadual de Londrina, Londrina-Paraná.

Santos, S. C. (2001). O processo de ensino-aprendizagem e a relação professor-aluno: aplicaçáa dos «sete princípios para a boa prática na educação de ensino superior». Caderno de Pesquisas em Administração, São Paulo, 8 (1).
Silva, A. C. R. (2003). Metodologia da Pesquisa Aplicada à Contabilidade. São Paulo: Atlas.

Skaalvik, E. M. \& S. Skaalvik (2011). Teacher job satisfaction and motivation to leave the teaching profession: Relations with school context, feeling of belonging, and emotional exhaustion. Teaching and Teacher Education, 27 (6), 1029-1038. http://dx.doi. org/10.1016/j.tate.2011.04.001

Telfer, R. \& T. Swan (1986). Teacher motivation in alternate promotion structures for NSW high schools. The Journal of Educational Administration, 24 (1), 38-57. http://dx.doi.org/10.1108/eb009908

Thomson, M. M., J. E. Turner \& J. L. Nietfeld (2012). A typological approach to investigate the teaching career decision: Motivations and beliefs about teaching of prospective teacher candidates. Teaching and Teacher Education, 28 (3), 324-335. http://dx.doi. org/10.1016/j.tate.2011.10.007

Vaz, A. C. (2010). O papel da gestão na motivaçâa profissional de docente. Dissertação em Educação. Universidade Católica de Brasília, Brasília - DF.

Viana, J. C. C. R. (2008). O perfil motivacional do docente da rede estadual de ensino fundamental na Paraíba. Dissertação em Administração. Universidade Federal da Paraíba, João Pessoa.

Weiner, B. (1992). Human motivation: Metaphors, theories and research. Newbury Park, Ca.: Sage.

Fecha de recepción: 15 de octubre de 2015 Fecha de aceptación: 21 de octubre de 2015 Correspondencia: alinicont@gmail.com carol_spletsch@yahoo.com.br vania@furb.br 